This is an electronic reprint of the original article. This reprint may differ from the original in pagination and typographic detail.

Author(s): Pirkkalainen, Henri; Jokinen, Jussi; Pawlowski, Jan M.; Richter, Thomas

Title: $\quad$ Overcoming Cultural Distance in Social OER Environments

Year: $\quad 2014$

Version:

Please cite the original version:

Pirkkalainen, H., Jokinen, J., Pawlowski, J. M., \& Richter, T. (2014). Overcoming Cultural Distance in Social OER Environments. In S. Zvacek, M. T. Restivo, J. Uhomoibhi, \& M. Helfert (Eds.), CSEDU 2014 : Proceedings of the 6th International Conference on Computer Supported Education. Vol. 1 (pp. 15-24). Insticc press. https://doi.org/10.5220/0004719300150024

All material supplied via JYX is protected by copyright and other intellectual property rights, and duplication or sale of all or part of any of the repository collections is not permitted, except that material may be duplicated by you for your research use or educational purposes in electronic or print form. You must obtain permission for any other use. Electronic or print copies may not be offered, whether for sale or otherwise to anyone who is not an authorised user. 


\title{
Overcoming Cultural Distance in Social OER Environments
}

\author{
Henri Pirkkalainen ${ }^{1}$, Jussi P.P. Jokinen ${ }^{1}$, Jan M. Pawlowski ${ }^{2}$, and Thomas Richter ${ }^{3}$ \\ ${ }^{1}$ University of Jyväskylä, Mattilanniemi 2, Agora Building, FI-40014 Jyväskylä, Finland \\ ${ }^{2}$ Ruhr West University of Applied Sciences, 45407 Mülheim, Germany \\ ${ }^{3}$ University of Duisburg-Essen, Universitätsstrasse 9, 45141 Essen, Germany
}

\{henri.j.pirkkalainen, jussi.p.p.jokinen\}@jyu.fi,jan.pawlowski@hs-ruhrwest.de,Thomas.Richter@icb.uni-due.de

\begin{abstract}
Keywords: Barriers, culture, TEL, cultural distance, social software, OER
Abstract: $\quad$ Open educational resources (OERs) provide opportunities as enablers of societal development, but they also create new challenges. From the perspective of content providers and educational institutions, particularly, cultural and context-related challenges emerge. Even though barriers regarding large-scale adoption of OERs are widely discussed, empirical evidence for determining challenges in relation to particular contexts is still rare. Such context-specific barriers generally can jeopardize the acceptance of OERs and, in particular, social OER environments. We conducted a large-scale $(\mathrm{N}=855)$ cross-European investigation in the school context to determine how teachers and learners perceive cultural distance as a barrier against the use of social OER environments. The findings indicate how nationality and age of the respondents are strong predictors of cultural distance barrier. The study concludes with identification of context-sensitive interventions for overcoming the related barriers. These consequences are vital for OER initiatives and educational institutions for aligning their efforts on OER.
\end{abstract}

\section{INTRODUCTION}

Open educational resources (OERs) and practices to increase the sharing behavior of both educators and learners have been widely discussed in the domain of technology-enhanced learning (TEL) in the recent years. Online OER environments have been receiving attention because they serve as platforms for educators and learners to search and collaborate in. While many initiatives have been rather successful in keeping their OER environments in linear growth with increased amounts of published learning objects (Ochoa, 2009), maintaining active participation in and use of the OER environments remains the key challenge (Chen, 2010; D'Antoni 2008; Yuan et al., 2008). Existing research has been discussing various barriers that hinder or negatively affect OER adoption and use in teaching and learning activities. Such barriers relate to lack of awareness of OER and related copyright and intellectual property issues (Chen, 2010; Yuan et al., 2008; Hatakka, 2009), Institutional regulations and restrictions (Yuan et al., 2008; Hatakka, 2009), quality of resources (Hatakka,
2009; Richter \& Ehlers, 2011), and so on. As indicated by Chen (2010) and Hatakka (2009), not all challenges become significant, and barriers can be highly context-dependent. Therefore, many challenges could occur depending on the types of educational practices in the region or country and depending on the background, experiences, and perceptions of the educators and learners. One of the crucial topics for OER is cultural distance. As depicted by Hatakka (2009), cultural expressions also pose a challenge for understanding where language plays a strong role in inhibiting factors of OER.

The OER movement must consider the implications of knowledge sharing carefully, as many initiatives are basing their OER services and environments on social software-like functionalities that place educators and learners as key users to share, discuss, and collaboratively work on OERs (Ha et al., 2011; Sotiriou et al., 2013). Knowledge sharing is implying, in this case, not only sharing of OER but also the collaborative practices around the resources. The established connection between social software and OERs to social OER 
environments can have multiple potentials. As indicated by research on social software in provision of teaching and in pedagogy, these services can provide positive learning outcomes and intriguing experiences for both educators and learners when applied to teaching practices (Hall \& Davison, 2007; Wever et al., 2007). However, the connection to OER places educators even more in a key role in OER environments with a strong focus on functionalities for networking and collaboration. Such environments build on international educator and even learner communities, providing materials across subject areas of the curriculum in various languages. As elaborated by Lai and Chen (2011) and Zhang (2010), adoption of specific social software services might be highly country dependent because of differences in culture and context. As argued by Agarwal (2007), there are various challenges to knowledge sharing while so-called cultural distance becomes highly important in a context where people deal within online social environments. The finding is in line with the studies of Noll et al. (2010) and Pallot et al. (2010) that deal with collaboration across distance. However, the current literature has been very limited in studies that could inform the domain regarding how strong those cultural barriers are perceived across nations, within educator and learner communities that adopt these social OER environments. Such information is necessary for any educational institution or educator evaluating the suitability of the OER environments to own purposes. This information is also vital for OER providers to understand the barriers for their end users and the circumstances around those challenges.

We address this gap by the means of a large-size exploratory study $(\mathrm{N}=855)$ to inspect how strongly cultural distance barrier is perceived by teachers and learners in primary and secondary schools across Europe. Within our inspection, the aim is not to define culture or different types of influencing factors for it. However, we aim to understand in a cross-national view to what extent teachers and learners perceive cultural distance when dealing with OER online social environments. In addition to observing the barriers of cultural distance, our study strives to understand possibilities to overcome such barriers. These interventions are discussed on a technical and nontechnical level to describe the possibilities for OER content and technology providers as well as educational institutions.

The structure of the paper is as follows. The next section describes the theoretical background for culture and social software focused OER. Then, we will describe the methodology for the study. The results are presented in the fourth section, followed by the discussion of the results. The paper concludes by describing the limitations of this study as well as the key contributions to both research and practice.

\section{THEORETICAL BACKGROUND}

OER has been a widely discussed topic since 2002 when UNESCO coined the term in a global OER forum. OER was described (2002) as "technology enabled, open provision of educational resources for consultation, use and adaptation by a community of users for non-commercial purposes." The research on OER has been focusing on potential usage in varying contexts, ranging from higher education (Yuan et al., 2008) and schools (Richter \& Ehlers, 2011) to the corporate world (Manisha \& Bandyopadhyay, 2009; Ha et al., 2011). Those cross-context studies are often connected to barriers or challenges that hinder OER adoption. These barriers are discussed on various levels, on the missing organizational support mechanisms (Chen, 2010; Yuan et al. 2008), lack of infrastructure and proper hardware (Chen, 2010; Hatakka, 2009), lack of quality of the resources as well as in the provided services (Clements \& Pawlowski, 2011), and so forth. Existing research is yet to define in which contexts and even in which countries or regions certain barriers are likely to occur. One of the key issues in the literature that could explain contextual differences is culture and specifically, culture of OER sharing (Davis et al., 2010; Richter, 2011).

As argued by Kroeber and Kluckhohn (1952), there is no definite concept of culture. Scheel and Branch (1993) provided one possible description for it as a manifestation of patterns of thinking and behavior relating to social, historical, geographical, political, economical, technological, and ideological environment. Studying cultural factors or differences for TEL is not an entirely new focus. Richter and Pawlowski (2007) studied standardization of context metadata within e-learning environments. They defined cultural metadata and showed a number of factors concerning language, which is one of the key cultural factors. Those range from language, communication style, specific symbols, attitudes and perceptions of learners and educators, and culturespecific idioms, to more technological issues, such as types of date and time formats. As elaborated by a number of researchers, studying cultural differences 
can be problematic. Church and Katigbak (1988), e.g., argue that while "one needs culture-comparable constructs to make cross-cultural comparisons, their use may distort the meaning of constructs in some cultures or miss their culture-specific aspects." Goldschmidt (1966) even goes a step further, claiming that it generally is inappropriate to compare cultures at all, as every "institution" needs to "be seen as a product of the culture within which it developed. It follows from this that a cross-cultural comparison of institutions is essentially a false enterprise, for we are comparing incomparables." As a consequence, most culture comparisons are limited to value systems, as there is a hope that there are general values, which at least play a certain (even if not exactly the same) role across most of the human societies. However, in such investigations, the position of the researcher rarely is neutral, as the perspective taken to choose particular values for comparison already is culturally biased. In a multinational study, Schwartz and Bilsky (1990) investigated 36 values in comparative culture research and found that just seven of those had the meaning of values across the investigated contexts. In order to overcome this challenge, we focus on educational contexts and define culture, according to Oetting (1993), as "customs, beliefs, social structure, and activities of any group of people who share a common identification and who would label themselves as members of that group" (herein, perceptions of educators and learners in the educational context).

Henderson (2007) described how the process of preparation of e-learning materials demands the analysis of cultural influence, especially when the separation of local, national, and international context of usage can be identified. Such separation of contextual modes is becoming even more prominent for OER as initiatives strive for aggregation of existing repositories or databases in one single access point (Ha et al. 2011; Sotiriou et al., 2013). Additionally, social interaction and collaboration mechanisms are crucial components of such environments, and they increase cultural influence. One way to address such cultural influences is to focus on cultural distance. The concept of cultural distance depends on the recipient's perceptions on how strong the difference between the home culture and host culture are; the greater the perceived difference, the more difficult it is to establish a relationship (Ward et al., 2001). As an example, such distance can be perceived when educators or learners try to adopt OERs or teaching practices that are exceptional or unfitting to their own context. Another case of clashing home and host culture could be when an educator is doubtful of joining a relevant conversation with a colleague from a distant location because it would not take place in her mother tongue. Investigating cultural distance provides information that crucially is required to decide when conflicts may occur in OER environments. In the context of OERs, cultural distance becomes a highly relevant issue when educators and learners shall use OERs from different contexts; being constantly exposed to potential learning materials and forms of collaboration that may not fit to their own preferences of working and learning or take place in their own native language.

Recent research in the educational domain shows the increasing interest toward social software. Social software can be described as a set of tools to enable interactive collaboration, managing content, and networking with others (Wever et al., 2007). While the application of social environments has been discussed as a support mechanism for pedagogy (Lai \& Chen, 2011; Hall \& Davison, 2007), the connection to OER is rather emerging. The focus of social and collaborative services in OER environments sets educators as key users of the environments. Such "collaborative content federations" (Ha et al. 2011; Sotiriou et al., 2013) often provide materials in various languages, while the environments are not equally translated to support international users. While language skills and preferences vary across educational level and countries, the preferences of educators and learners in terms of language or collaboration are not well known. As elaborated by Agarwal et al. (2007), knowledge-sharing activities of teachers and learners can be highly influenced by culture. Similarly, Noll et al. (2010) and Pallot et al. (2010) evidenced that culture and language distance are two of the strongest barriers in distributed collaboration, and this sets the focus for our study.

OER as well as social software research focuses on understanding particular barriers in order to overcome them. Solutions and interventions have been suggested as possible mechanisms to lower the barriers (Chen, 2010; Yuan et al., 2008; Hatakka, 2009), such as technology and policy-related strategies to be implemented (Chen, 2010) or shortto long-term drivers or enablers from cooperation to OER development (Yuan et al., 2008). Within this paper, we aim to determine mechanisms for lowering the barriers of cultural distance. 


\section{METHODOLOGY}

Our study targeted school education, focusing on teachers and learners in primary and secondary schools across Europe. The aim was to find out 1) how far cultural distance is perceived as a barrier against the use of social OER environments, and 2) how to overcome such barriers.

In our study, we first investigated cultural distance barriers in general, by asking teachers and learners for their experiences regarding the use of (selected) social OER environments; we wanted to know which aspects in particular were understood as the major barriers against the use of existing OER environments. Second, we asked the participants to determine the improvement potential for the experimentally used social OER environments, in order to identify possible interventions that would be appropriate for overcoming the found barriers.

\subsection{Operationalization of "Cultural Distance Barriers"}

To address cultural distance barriers and to observe which aspects can predict its significance, a decision was made to operationalize related barriers into this one latent factor. The focus of the source literature has not fully covered all of the barriers to a culture of sharing and collaborating in OER environments. As discussed, studying cultural influence factors in a holistic setting is impossible because of the wide variety of cultural aspects and the lack of knowledge regarding their distinction (dependencies and interrelations). The approach for the operationalization and selection of related challenges was set based on the previously presented understanding of cultural distance by Ward et al. (2001). For our investigation, we focused on barriers that are related to aspects of sharing and collaboration in social OER environments, the language of collaboration, and the distance of the identified OERs they come across.

As the found literature has not focused on social OER environments, modification of approaches to analyze barriers was necessary. A particular barrier towards cultural distance that was found in the literature was related to knowledge sharing and collaboration (Noll et al., 2010; Pallot et al., 2010). This barrier was related to language component of cultural distance, as well as the perceived difference of the home and host context. As a common language is one of the greatest challenges for organizing distributed work (Noll et al., 2010; Pallot et al., 2010), we focused on this in our context. In our setting, teachers and learners are connected within an international community. The first item for our survey was therefore: "Language is the key". I only want to contribute to online communication/collaboration when my own native language is used (based on Noll et al. (2010) and Pallot et al. (2010)).

Richter \& Ehlers (2011) and Hatakka (2009) discussed that teachers might experience an unmanageable distance when adapting resources from other cultural contexts particularly regarding language and culture-specific idioms. The second item chosen for the survey was: Challenging to apply digital educational resources which are culturally distant (values, symbols, beliefs, etc.) from my own (based on Hatakka (2009) and Richter and Pawlowski (2007)).

Distance can also result from a lack of trust against the authors of the OERs (Hatakka, 2009; Pallot et al., 2010). While cultural distance can be perceived without geographical or temporal distance (Noll et al., 2010), the notion of geography was included in the item to highlight the very likely geographic dispersion of users in the social OER environment. Thus, the third item was: Impact of cultural and geographical distance - Lack of trust towards authors of digital educational resources (based on Hatakka (2009) and Pallot et al. (2010)).

Another important issue that derived from OER research was that OERs often do not provide enough information on the context where they were created and designed for (Davis et al., 2010). This led to our fourth item: Digital educational resources do not give enough information on the context where it is / was created and used (based on Davis et al. (2010)). The focus was therefore set to study how the participants perceive OER that is created in a context that is distant from own, whether the distance has impact on the trust for the authors and providers of OER and if language plays a strong role for collaboration. The starting point of our analysis was, that these four culture barrier questionnaire items were indicators of a single latent factor.

\subsection{Data Collection}

The data collection was conducted within the scope of the Open Discovery Space project (ODS). The ODS (Sotiriou et al., 2013) is an EU-funded FP7 project that builds a social OER environment for the European school context around a federation of learning content repositories. In the context of the 
ODS project, workshops for teachers and learners were organized. In the context of these workshops, existing social OER environments were introduced: OERs within their topics of teaching (and interest) exemplarily were used, and the potentials for adopting these environments were discussed. In the end of the workshops, the participants were asked to complete a questionnaire that addressed the particular challenges the participants experienced in this experiment and their expectations toward the upcoming ODS portal. The role of each workshop was to introduce the concepts addressed in the questionnaire. This ensured that the respondents were aware of what was asked from them.

One of the main parts of the ODS-questionnaire focused on aspects that we addressed as being related to cultural distance. The depth of the survey, however, goes beyond the scope of this paper. The instrument was operationalized with a total of 23 items and 10 open questions. Other parts of the questionnaire addressed organizational and qualityrelated OER-barriers that were derived from OERliterature. The purpose was to see which barriers the respondents perceive as most critical. The second part of the survey included open questions asking for enablers and interventions to overcome such challenges. The inspection was solely limited to perceived cultural distance because of its significance in the analysis of both quantitative and qualitative data.

Approximately 2300 educators and learners participated in 92 workshops in 19 European countries. While schoolteachers were mainly expected to participate, ODS invited students, educators from higher education as well as policy makers to understand the restrictions and possibilities for influencing the European education system. The selection of schools was based on the longitudinal engagement plan of ODS for the schools of each country. Most of the workshops took place in a face-to-face setting and were organized by the local project partners. Four workshops were conducted online through video conferencing facilities. Each workshop focused on one or more particularly selected OER environment(s). The main criterion for the selection of the OER environments was related to supported social functionalities around the educational resources. The most frequently demonstrated environments within the workshops were:

- OpenScout - OER for business and management (http://learn.openscout.net)

- OSR - Open science resources (http://www.osrportal.eu)
- Discover the Cosmos - Astronomy resources (http://www.cosmosportal.eu)

- Photodentro - A Greek Digital Learning Object (http://photodentro.edu.gr/lor/)

In the study, 1175 individuals from 19 European countries actually completed the questionnaire (nonresponse rate of 49\%). The countries were: Austria, Belgium, Croatia, Cyprus, Estonia, Finland, Germany, Greece, Ireland, Italy, Latvia, Lithuania, the Netherlands, Portugal, Serbia, Spain, and the United Kingdom. The respondents were mainly educators in primary, secondary, and higher education. Additionally, a number of learners and policy makers completed our survey. For the analysis herein, we excluded policy makers and participants representing higher education and only considered the responses of teachers and learners from primary and secondary school education $(\mathrm{N}=855)$. The reason was to avoid mixing differing contexts of higher education and schools together. Additionally, the interventions could also be discussed more accurately when restricting the focus to a certain context. Some questionnaires were only partially completed. Because this was particularly the case in Romania, we finally excluded the country's participants from the evaluation. The mean age of the respondents was 37.4 years $(\mathrm{SD}=11.1)$. Among the respondents, $69 \%$ were female, and $83 \%$ were teachers.

\subsection{Data Analysis}

The previously discussed four questionnaire items were used in constructing a summated scale to represent the cultural distance barrier for the study at hand. The reliability of the items was confirmed using principal axis factoring. Factor loadings over .50 were expected, as well as loadings relatively comparable in size. The reliability coefficient of the cultural distance scale was calculated using both factor score covariance and Cronbach's alpha. After the reliability inspections, we proceeded to construct a summated scale by calculating the average of the four cultural distance barrier items. The average of all variables was used instead of factor loadings, because the study was exploratory and we wanted to retain the original scale (from one to five). Any missing values for the culture barrier items were imputed to replace missing data. The amount of missing values for the selected four items was between $6.1 \%$ and $7.2 \%$. Analysis of the missing value patterns revealed no significant differences between the gender and the role of the respondents. 
To explore the country differences regarding experienced barriers based on cultural distance, a generalized linear model (GLM) predicting cultural distance barrier was constructed. The fixed factors of the model were, in addition to the country of the respondent, the gender and professional status (teacher or learner). The age of the respondent was used as a covariate. An intercept was included in the model, which was full factorial, e.g., interaction effects between the fixed factors were also tested.

The second part of our study was to look for potential interventions against the cultural distance barrier. This part of the survey applied open questions purposing to understand what could solve or lower the particular barriers reported by the respondents. The following open questions were applied to our survey for this purpose:

- "How COULD TECHNOLOGY SOLUTIONS AROUND RESOURCES SOLVE THESE PROBLEMS (E.G., ONES PRESENTED TO YOU/WHICH YOU TRIED IN THE WORKSHOP)?”

- "HOW WOULD YOU IMPROVE THE CURRENT SOLUTION?"

- "WHAT KIND OF HELP/TRAINING/TOOLS WOULD YOU NEED?"

Our intention was to find solutions to overcome the barrier of cultural distance. Key interventions against cultural distance barrier were found through clustering of the responses, which was accomplished with a focus on technical and organizational issues. The findings were understood as guiding steps for the ODS implementation.

\section{STUDY RESULTS}

The factor loadings for the four culture barrier questionnaire items that were derived in section 3.1 are displayed in Table 1. The Kaiser-Meyer-Olkin measure of sampling adequacy was .73, and Bartlett's test of sphericity was statistically significant $(p<.001)$. The single factor solution displayed in Table 1 had an eigenvalue of 2.2, and explained $56 \%$ of the variance of the four cultural distance barriers. The reliability of the scale using factor score covariance was .74, and Cronbach's alpha was .72. The mean of the summated scale of culture barrier, calculated as the mean of the four items, was $2.65(\mathrm{SD}=0.95)$, and both its theoretical and observed range was 1.00-5.00.
Table 1: Factor loadings for principal axis factoring of cultural distance barrier items.

\begin{tabular}{lcc}
\hline & Ltem & Loading \\
\hline Challenging to apply digital educational & \\
resources which are culturally distant (values, & .71 \\
symbols, beliefs etc.) from my own. & \\
Impact of cultural and geographical distance - & \\
Lack of trust towards authors of digital educational & .69 \\
resources. \\
$\quad \begin{array}{l}\text { Digital educational resources do not give } \\
\text { enough information on the context where it is / was }\end{array}$ \\
created and used. \\
"Language is the key." I only want to contribute \\
to online communication/collaboration when my \\
own native language is used.
\end{tabular}

Note. $N=861$.

The results of the general linear model predicting the barrier of cultural distance are displayed in Table 2 . The number of observations for GLM was smaller than for Principal Axis Factoring, because six respondents had failed to report their age and were therefore removed from this analysis. From the main effects, age and country were statistically significant. Gender, role (teacher/learner), and the interaction effects between the fixed factors were nonsignificant. The coefficient of the model intercept was 1.88 , and the upper and lower bounds of $95 \%$ confidence interval were 1.50 and $2.29, p<$ .001 . The coefficient of the age was.01 [.01, .02], $p$ $<.001$. In other words, the older participants were more likely to report a higher barrier of cultural distance.

Table 2: General linear model predicting cultural distance barrier.

\begin{tabular}{llll}
\hline Source & df & $F$ & sig. \\
\hline Corrected Model & 55 & 3.6 & $<.001$ \\
Intercept & 1 & 227.3 & $<.001$ \\
Age & 1 & 15.8 & $<.001$ \\
Gender & 1 & 2.9 & .088 \\
Country & 17 & 4.7 & $<.001$ \\
Role: teacher/learner & 1 & 1.5 & .227 \\
Gender $\times$ country & 17 & 1.0 & .483 \\
Gender $\times$ role & 1 & 2.6 & .111 \\
Country $\times$ role & 11 & 0.8 & .581 \\
Gender $\times$ country $\times$ role & 6 & 0.4 & .867 \\
\hline
\end{tabular}

Note. $N=855$. Model $R$ squared $=.20$, adjusted $=.14$.

The GLM revealed how the cultural distance barrier depends on the nationality and age of the respondent. Results also indicated how the roles of teacher or learner do not explain the barrier of cultural distance. This implies that teachers are not more likely to perceive cultural distance barrier than learners and vice versa. The mean of the cultural 
distance barrier variable for learners was 2.52 (SD = $1.03)$, and for teachers $2.68(\mathrm{SD}=0.93)$. For both males and females, the mean was 2.65 , and standard deviations, respectively, were 0.93 and 0.96 . The findings imply that the perceived cultural distance is not a barrier for majority but is likely to occur depending on the age and nationality of the teacher/learner.

The means of the cultural distance barrier variables between the countries are shown in Figure 1. Based on post-hoc analysis (least significant difference) we identified Croatia, Latvia, and Estonia to be the countries with statistically significantly high means as compared to the countries with relatively low means: Austria, Belgium, Spain, Finland, Ireland, the Netherlands, Portugal, and Serbia. The implications of these results will be discussed in the last section of this paper.

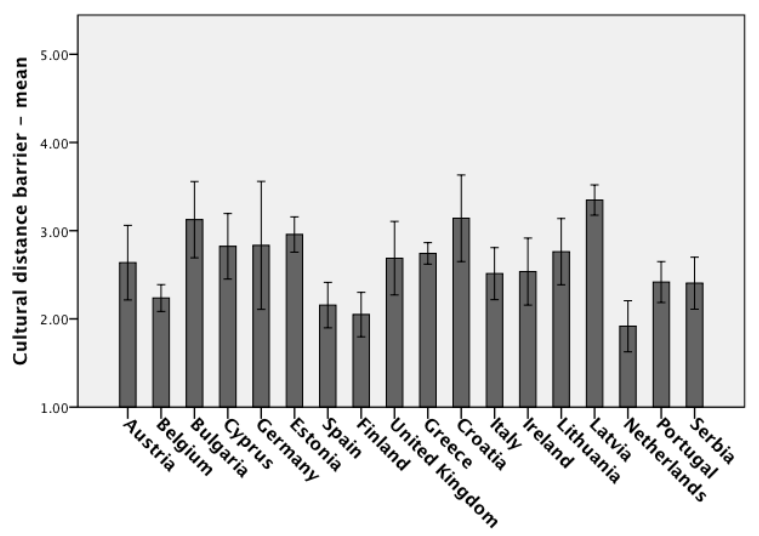

Figure 1: Country separation for cultural distance barrier. Smaller lines denote $95 \%$ confidence interval.

\section{INTERVENTIONS}

As previously explained, our research was not limited to investigating which parameters particularly affect cultural distance. In addition, we also studied interventions for the corresponding barriers. The answers we received on the open questions asking for potential mechanisms to overcome the barriers were related to both technological and organizational/contextual levels: Overcoming cultural distance barrier, firstly, regards the quality and suitability of the OER environment (technology) and, secondly, the community and OER initiatives themselves, as they act as change enablers toward new practices of sharing. In Table 3 , both aspects for interventions are discussed.

In addition to the technical interventions, the respondents made recommendations to remove the barriers on the organizational level as well as the OER community-level (Table 4).

The results on interventions to potentially overcome or reduce barriers that are related to cultural distance indicate the key opinions of teachers and learners of our study. As shown in the technical dimension, the provision of functionalities as well as the variety of resources has to match the particular requirements and needs of the individual users. As presented in the previous section, not all users in the different European countries have the experience or are able to collaborate in a foreign language or to adopt OER that might be culturally distant. The key intervention seems still to be stimulating a change in OER knowledge-sharing practices by leading examples through the engagement and training activities of the OER initiatives that also provide the OER environments.

Table 3: Technical interventions.

\begin{tabular}{|c|c|c|}
\hline & Key aspect & Explanation \\
\hline \multirow[t]{3}{*}{ Multilinguality } & $\begin{array}{l}\text { Resource availability in own native } \\
\text { language }\end{array}$ & $\begin{array}{l}\text { Many are unwilling or cannot handle foreign } \\
\text { language }\end{array}$ \\
\hline & $\begin{array}{l}\text { Equal distribution of materials in different } \\
\text { languages }\end{array}$ & $\begin{array}{l}\text { Users need to have materials that are easy for them } \\
\text { to apply }\end{array}$ \\
\hline & Portal translated to own language & $\begin{array}{l}\text { Shows that their language is important for the } \\
\text { provider/developer }\end{array}$ \\
\hline \multirow[t]{2}{*}{ Functionalities } & $\begin{array}{l}\text { Methods for communication/ } \\
\text { collaboration }\end{array}$ & $\begin{array}{l}\text { Synchronous/asynchronous, } \\
\text { Formal/informal }\end{array}$ \\
\hline & Sharing and collaborating & $\begin{array}{l}\text { With anyone, } \\
\text { With selected people/group/community }\end{array}$ \\
\hline User interface & $\begin{array}{l}\text { Intuitive and localized for specific user } \\
\text { groups }\end{array}$ & $\begin{array}{l}\text { Providing customized views for s/learners from } \\
\text { different countries/regions }\end{array}$ \\
\hline $\begin{array}{l}\text { Metadata } \\
\text { provision }\end{array}$ & Rich and versatile metadata & $\begin{array}{l}\text { E.g., indicating clearly for each resource, the context } \\
\text { where it is created/used }\end{array}$ \\
\hline $\begin{array}{l}\text { Trusted } \\
\text { communities }\end{array}$ & $\begin{array}{l}\text { Quality mechanisms, indicating when } \\
\text { resources are from reliable and active } \\
\text { source }\end{array}$ & $\begin{array}{l}\text { Aiming to increase trust toward user-/- generated } \\
\text { content }\end{array}$ \\
\hline
\end{tabular}




\section{DISCUSSION AND CONCLUSIONS}

Within this paper we investigated the perception of cultural distance as a barrier against the use of social OER environments and ways to overcome those barriers. The perceptions of teachers and students from school education were in key role for defining whether they feel such cultural distance when using OERs and collaborating with international communities around those OERs. Our study focused on barriers against social software services that are provided for/within OER environments, creating social OER environments. As the understanding on how cultural distance barrier is perceived and how to overcome related challenges was rather limited, the findings of this study can provide a significant contribution to fill this gap. The results indicate how age and nationality affect the significance of cultural distance barrier. Younger respondents are more likely to experience a lower level of barrier when dealing with learning resources from and online collaboration with a distant culture. The results also evidence which of the 18 investigated countries' participants perceive cultural distance as a barrier. Interestingly, the professional role of the respondents did not significantly affect the perceptions towards cultural distance barrier.

The findings indicated that cultural distance is statistically significantly perceived as a barrier, particularly in the Baltic countries of Latvia and Estonia, and in Croatia. However, our study cannot explain why some countries had relatively low means in this context (e.g., Belgium, Spain, Finland, and the Netherlands). More research is needed to indicate the general validity of our results as well as to explain the reasons for the between-country deviations. While one argument could be that language skills and preferences differ between countries, such results might also be explained by awareness on OER in general. If the schools have a strong background in using textbooks, a rapid change to apply and modify OERs provided by an international community might not be realistic or trivial. Such a basic change of thinking and towards practical ways to approach preparation of lectures and teaching can be problematic. However, the findings do indicate how applying OERs that are prepared in/for a specific national/educational context might raise even more significant barrier within another context.

The influence of age regarding the perceived impact of cultural distance barrier is an important finding as it has not yet been reported in the context on OER. However, Onyechi and Abeysinghe (2009) reported similar results regarding the use of technology; they found that users under 35 years old are more likely to accept collaborative tools.

Regarding interventions against barriers that are related to cultural distance, we found both technical and nontechnical issues. The respondents elaborated on how social OER environments must fulfill their basic needs in terms of the quality of provided services and resources, and multilinguality. In order to generally reach a higher level of acceptance, OER initiatives should not just provide the technology for the OER usage but additionally foster the change toward openness in education. In this context, intense cooperation with the schools is required, e.g., approaching joint campaigns and collaborative efforts to contextualize/translate OERs for the contexts of the schools.

Our study and the related results have limitations: First of all, our results need to be limited to the context of school education, where the research took place. It is yet unclear to which extent those can be transferred to other educational scenarios. The participating schools were selected from existing networks of the partner organizations in the project. In many cases, only teachers from one specific area of the country participated. Thus, the sample might not be fully representative for all schools in the country. Additionally, we did not

Table 4: Nontechnical interventions.

\begin{tabular}{|c|l|}
\hline Key aspect & \multicolumn{1}{|c|}{ Explanation } \\
\hline $\begin{array}{c}\text { Translating/localizing } \\
\text { resources to fit the context }\end{array}$ & $\begin{array}{l}\text { Setting a group within small communities and schools to translate the best materials } \\
\text { for that purpose into their own language. Setting contests that include } \\
\text { translation/localization/adaptation tasks, rewarded by the ODS network in cooperation } \\
\text { with the local schools. Rewards could be free access to events such as summer school, } \\
\text { training events, or conferences. }\end{array}$ \\
\hline $\begin{array}{c}\text { OER initiative } \\
\text { stimulating the creation of } \\
\text { knowledge-sharing } \\
\text { culture in schools }\end{array}$ & $\begin{array}{l}\text { Teacher's practices still vary for sharing their resources as well as using resources } \\
\text { provided by others, even within their own schools. This process should happen from the } \\
\text { bottom-up and then expand to the European level. To create this culture of sharing } \\
\text { resources, experiences, and competencies with others, the OER initiatives should motivate } \\
\text { teachers on local, national, and international levels to do so by showing some good } \\
\text { examples of collaboration across countries. }\end{array}$ \\
\cline { 2 - 3 } & $\begin{array}{l}\text { OER initiatives should aim to be open communities focusing on support and } \\
\text { experience exchange. Teachers and learners should feel a sense of belonging and be given } \\
\text { something that they feel comfortable using. Otherwise they might feel afraid that they'll be } \\
\text { criticized about what they wrote or contributed. }\end{array}$ \\
\cline { 2 - 2 } & $\begin{array}{l}\text { OER initiatives should provide opportunities for teachers to attend international } \\
\text { training events, in order to help overcome cultural barriers in trusting resources from } \\
\text { different cultures, as well as to feel that they are members of an international community. }\end{array}$ \\
\hline
\end{tabular}


investigate the previous experience of the participants with OER. In retrospective, this might have been valuable information for both the analysis as well as the interpretation of the actually received results. We do acknowledge that the actual barriers differ between teachers in different contexts and educational institutions. However, this study focused on understanding to which extend teachers perceive cultural distance barrier when using OER environments, not to explain the types of barriers teachers face nor various cultural influencing factors that affect their behavior.

As the research was conducted as a part of the requirements analysis for the development of the social OER environment for the ODS project, the practical implications of our study are clear, especially for OER providers and developers: The results are relevant for any engagement activities with teachers and learners in similar OER scenarios. As OER provision through resource-/repositoryfederations becomes even more frequent, our results support the decisions on how to overcome some typical challenges. The results also give pragmatic suggestions to engage through the younger teachers as early adopters and community builders. Our findings can therefore help to significantly reduce efforts placed for the identification of needs and requirements of teachers and learners during the development of social OER environments.

Our contribution to research lies in the exploratory factor analysis conducted within this study. The identification of the factors representing barriers that are related to cultural distance provides a meaningful construct for future quantitative studies on OERs. Future studies on the topic could apply the proposed construct on variance models to verify and enrich existing theories on, e.g., technology acceptance. It would be important to address further studies to explain which barriers (e.g., lack of support within the organization, lack of awareness on OER) can predict barriers on the level of cultural distance.

\section{ACKNOWLEDGMENTS}

This research has been co-funded by the European Commission through the CIP programme, Open Discovery Space, CIP-ICT-PSP-2011-5 297229 (cf. http://www.opendiscoveryspace.eu).

\section{REFERENCES}

Agarwal, N., Tan, K., \& Poo, D. (2007). Impediments to Sharing Knowledge Outside the School: Lessons Learnt From the Development of a Taxonomic Elearning Portal. International Conference on Information Systems.

Chen, Q. (2010). Use of Open Educational Resources: Challenges and Strategies. Hybrid Learning, 339-351.

Church, T.A. \& Katigbak, M.S. (1988). The Emic Strategy in the Identification and Assessment of Personality Dimensions in a Non-Western Culture. Journal of Cross-Cultural Psychology. 19, 140-163.

Clements, K. I., \& Pawlowski, J. M. (2011). User oriented quality for OER: Understanding teachers ' views on OER and quality. Journal of Computer Assisted Learning, 2007-2009.

Davis, H. C., Carr, L. a., Hey, J. M. N., Howard, Y., Millard, D., Morris, D., \& White, S. (2010). Bootstrapping a Culture of Sharing to Facilitate Open Educational Resources. IEEE Transactions on Learning Technologies, 3(2), 96-109.

D'Antoni, S. (2008). OPEN EDUCATIONAL RESOURCES DELIBERATIONS OF AN INTERNATIONAL COMMUNITY OF INTEREST. Retrieved from: https://oerknowledgecloud.org/sites/oerknowledgeclou d.org/files/Antoni_OERTheWayForward_2008_eng_0 .pdf

Goldschmidt, W. (1966). Comparative functionalism. University of California Press, Berkeley.

Ha, K., Niemann, K., Schwertel, U., Holtkamp, P., Pirkkalainen, H., Boerner, D., Kalz, M., et al. (2011). A novel approach towards skill-based search and services of Open Educational Resources. Metadata and Semantic ..., 1-12. Retrieved from http://www.springerlink.com/index/W7667752J630Q7 U3.pdf

Hall, H., \& Davison, B. (2007). Social software as support in hybrid learning environments: The value of the blog as a tool for reflective learning and peer support. Library \& Information Science Research, 29(2), 163187.

Hatakka, M. (2009). Build it and they will come?Inhibiting factors for reuse of open content in developing countries. The Electronic Journal of Information Systems in Developing Countries, 37, 116.

Henderson, L. (2007). Theorizing a multiple cultures instructional design model for e-learning and eteaching. Globalized e-learning cultural challenges.

Kroeber, A.L. \& Kluckhohn, C. (1952). Culture: A Critical Review of Concepts and Definitions. Vintage Books, New York. 
Lai, H.-M., \& Chen, C.-P. (2011). Factors influencing secondary school teachers' adoption of teaching blogs. Computers \& Education, 56(4), 948-960.

Manisha, \& Bandyopadhyay, T. (2009). A case study on content sharing by leveraging open educational resources framework. 2009 International Workshop on Technology for Education, 116-119.

Noll, J., Beecham, S., \& Richardson, I. (2010). Global software development and collaboration: barriers and solutions. ACM Inroads, 1(3), 66-78.

Oetting, E.R. (1993). Orthogonal Cultural Identification: Theoretical Links Between Cultural Identification and Substance Use. Drug Abuse Among Minority Youth: Methodological Issues and Recent Research Advances. 32-56.

Ochoa, X., \& Duval, E. (2009). Quantitative Analysis of Learning Object Repositories. IEEE Transactions on Learning Technologies, 2(3), 226-238. doi:10.1109/TLT.2009.28

Onyechi, G. C., \& Abeysinghe, G. (2009). Adoption of web based collaboration tools in the enterprise: Challenges and opportunities. 2009 International Conference on the Current Trends in Information Technology (CTIT), 1-6.

Pallot, M., Martínez-Carreras, M. A., \& Prinz, W. (2010). Collaborative Distance. International Journal of eCollaboration, 6(2), 1-32.

Richter, T. (2011). Adaptability as a Special Demand on Open Educational Resources: The Cultural Context of e-Learning. European Journal of Open and Distance Learning.

Richter, T., \& Ehlers, U.-D. (2011). Barriers and Motivators for Using OER in Schools. eLearning Papers, 23(March), 1-7.

Richter, T. \& Pawlowski, J. (2007). The need for standardization of context metadata for e-learning environments. e-ASEM Conference, Seoul, Korea.

Scheel, N. \& Branch, R. (1993). The role of conversation and culture in the systematic design of in-struction. Educational Technology. 33, 7-18.

Schwartz, S.H. \& Bilsky, W. (1990). Toward a theory of the universal content and structure of val-ues: Extension and Cross-Cultural replications. Journal of Personality and Social Psychol-ogy. 58, 878-891.

Sotiriou, S. A., Agogi, E., Athanasiades, N., Ramfos, A., Stracke, C. M., Richter, T., Pirkkalainen, H., et al. (2013). Open discovery space. Retrieved from: http://www.opendiscoveryspace.eu/sites/ods/files/open discovery_space.pdf.

UNESCO. (2002) UNESCO promotes new initiative for free educational resources on the Internet. Retrieved from:

http://www.unesco.org/education/news_en/080702 fre e_edu_ress.shtml [19 May 2012].

Ward, C. A., Bochner, S. \& Furnham, A. (2001). The psychology of culture shock. Hove: Routledge.
Wever, B. De, Mechant, P., Veevaete, P., \& Hauttekeete, L. (2007). E-Learning 2.0: Social Software for Educational Use. Ninth IEEE International Symposium on Multimedia Workshops (ISMW 2007), $511-516$

Yuan, L., MacNeill, S., \& Kraan, W. (2008). Open Educational Resources - Opportunities and Challenges for Higher Education Open Educational Resources Opportunities and Challenges for Higher Education. JISC CETIS, 1-35.

Zhang, L. (2010). Adoption of social software for collaboration. Proceedings of the International Conference on Management of Emergent Digital EcoSystems, 246-251. 